\title{
Island in an island - The suggestions for transportation improvement plan for Haidian Island, Haikou, Hainan
}

\author{
Rosalind Juo Ling Sia ${ }^{1}$, Xiaodan Zhu ${ }^{1}$ \\ ${ }^{1}$ Tourism College, Hainan University, Haikou Hainan
}

\begin{abstract}
Haidian Island, which situated at the Northern part of Haikou City of Hainan Province, is an island within a city. Haidian Island is unique in term of it's development which centered around an university, the Hainan University, besides some others important landmarks, such as Haikou city hospital, Baishamen municipal park, Golf Driving Range etc. All commercials, residential, recreational activities etc are planned to serve Hainan University in particular. The study, taking 'Haidian Island Area Development Control Plan' as case study, would like to look into the importance of transportation and traffic planning. The study used observation, site investigation and traffic study methods to gather data needed. Firstly the study analyzed the current state of transportation system for Haidian Island in accordance to the Island Development Control plan and Haikou master plan and identified the problems. Then, the study made some recommendations for these problems. The study highlighted the important of non-motorized, cycling and walking as the main transportation system for an education-based island and as supportive to domestic tourism activities found. The transportation planning suggested by the study took 'green and low-carbon' approaches considered the role of University as the core activity in the island.
\end{abstract}

\section{Introduction}

As a city with more than 200 million populations, even though is not a mega city, Haikou still stuck with transportation problems; there are some traffic circumstances such as congestion at peak time, poor road design and lack of integration between vehicle-human-landscape etc[1]. Haidian island, which forms a part of Haikou city, is the education hub for Hainan province, shares the similar transport problems.

Today, under the pressure of the fast-growing population and increasing number of tourists in Haidian island, transportation improvement has become essential. Transportation system is not merely a commuting channels but the vein of a city[2]. Transportation system encourages human interaction[3] and enlightens city liveliness[4]. Transportation plan then, plays an important role in ensuring these veins to function efficiently and serve it people well. This paper aimed to analysis the existing transportation problems in the Haidian Island Area Development Control Plan and then, put forward some suggestions to improve the plan, that meets the current development of Haidian island.

\section{Research area}

Hainan is an island which is located at the southern tip of china, is a tropical island which is famous for its summer sunshine and coconut tree. After the declaration of international touristic island [5], tourism has become the major industry that brings benefit to the economy of this island.

Haikou is the capital of Hainan province which is the center of administrative, economy and culture of Hainan. The research area of this paper, Haidian island is a small island situated at the northern part of Haikou (Figure 1). Haidian island is a typical delta island located in the Nandu river estuary. Haidian island is the biggest island in Haikou. There are Hainan University and Haikou hospital on this small island. Haidian island and Haikou city are separated by the Nandu river but they are linked by three major bridges, namely Century Bridge, Renmin bridge and Heping(Peace) bridge[6]. Haidian island, with the total land area of approximate 14 kilometer square[7], is hammer-head in shape, has flat terrain with load of river system, lakes, irrigation canals and ditches, that makes the island look really picturesque.

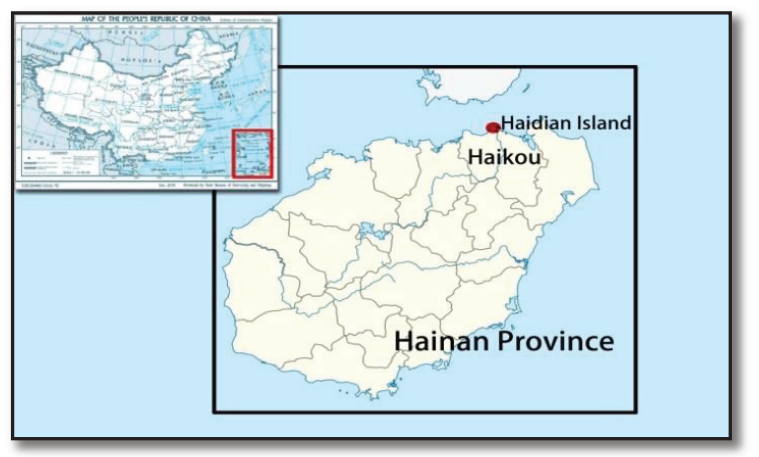

Figure 1. Location of Haidian Island at Haikou city of Hainan Province. (Source: Author illustration) 


\section{Research methods}

The study applied two general methods; observation and site investigation to obtain data needed. Firstly, the researchers look into all kinds of literature and master plans that related to Haidian island and decide on research topic. Then, to gather specific data on transportation, the author employed site investigation-cum-observation survey method to gather information on current situation, followed by traffic survey on vehicles and pedestrians on road during evening peak time around 17:30 o'clock to 18:30 o'clock.

\section{Spatial planning and current transportation problems}

\subsection{The Haidian development control plan}

The latest 'Haikou city master plan, 2005-2020' planned Haidian island as the education hub for Haikou city[8] in specific. Currently, the highest education institution of Hainan province, the Hainan University (HaiNu) is situated on this small island. The University is surrounded by mostly low-rise residential and community commercial shops, as well as a local park and others auxiliary facilities that cater for the resident needs.

According to the 'Haidian Island Area Development Control Plan' (after this refers as 'The Plan'), the development area covered a total of 1148.78 hectares with estimated population of 25.6 million, which including permanent residents of 15.5 million and not including of approximate 3 million students of Hainan University per annum[9]. The major landuse of Haidian island are designated for residential, however, there are some landmark building in between, including the Haikou people's Hospital, Baishamen Park besides Hainan University.

As stated in The Plan, the spatial distribution for Haidian island area are divided by 'one centre, one belt, two axes, five core areas' concept[9], as showed on Figure 2. One centre refers to Baishamen park as green leisure centre for the islanders and tourists; One belt refers to the round island, outer ring road which form the sightseeing and recreation route; Two axes refers to two major trunk roads, Haidian Wuxi road and Renmin Avenue; Five core areas refers to four residential zone and one educational institution, i.e. Hainan university zone, the west residential zone, the northeast residential zone, the northeast residential zone and the southeast residential zone.

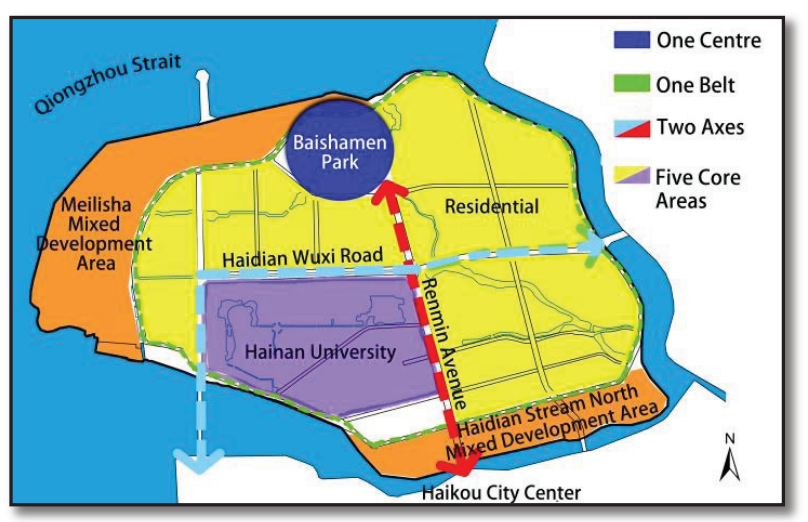

Figure 2. Spatial division of Haidian Island Area as suggested in Haidian Island Area Development Control Plan (Source: [9])

\subsection{The transportation plan}

The landuse area for roads and open space reserves are planned to be 218.59 hectares, about $19.03 \%$ of total developed area (1148.78 hectares) of Haidian island[9]. There are 9 areas of transportation planning stated in 'The Plan'. In this section, the paper first presented the contents stated in the 'Haidian Island Area Development Control Plan' (The Plan) for each areas; then, discussed the differences occured during the implementation of the plan which formed the current situation of each areas.

\section{Area 1: Road network plan}

The Plan: There are four types of road network in Haidian island; trunk distribution road, arterial distributions road, local distribution road and community access road. As showed in Figure 3, there are two types of trunk distribution road, which Haidian Wuxi road and Century Avenue are the score trunk roads while Heping (Peace) Avenue and Renmin Avenue are thr general trunk roads. These four roads also act as the external traffic that connect Haidian island to other areas within Haikou city. Arterial roads are those roads that connected to the trunk roads, which consist of Haidian Road 2, Road 3, Haidian middle Road 4, Seaview Road, Huandao Road etc. Table 1 showed the designated road widths and speed limits for the above mentioned road system.

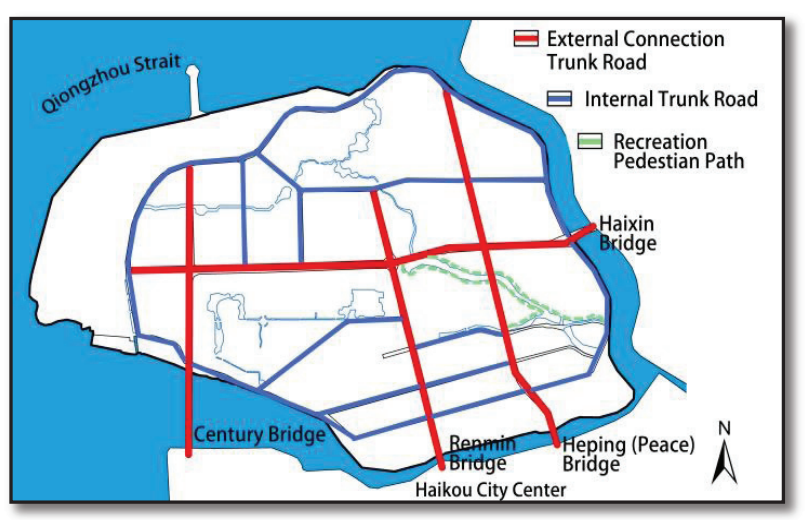

Figure 3. The road system of Haidian island(Source: [9])

Current situation: All designated roads had been constructed to serve the islanders daily usage. The 
existing roading networks of 4 different hierarchies roads are built according to the plan and municipal engineering requirement. The road widths of these roads are appropriated and no serious traffic jam observed even during peak hour.

Table 1. Road types, speed limits and widths of Road system in Haidian island

\begin{tabular}{|l|l|c|c|}
\hline \multicolumn{2}{|l|}{} & $\begin{array}{c}\text { Designated } \\
\text { Speed (km/h) }\end{array}$ & $\begin{array}{c}\text { Road } \\
\text { Width(m) }\end{array}$ \\
\hline 1 & $\begin{array}{l}\text { Core Trunk } \\
\text { distribution Road }\end{array}$ & $60-80$ & $50-70$ \\
\hline 2 & $\begin{array}{l}\text { General Trunk } \\
\text { distribution Road }\end{array}$ & $50-60$ & $40-60$ \\
\hline 3 & $\begin{array}{l}\text { Arterial Distribution } \\
\text { Road }\end{array}$ & $30-40$ & $30-40$ \\
\hline 4 & $\begin{array}{l}\text { Local distribution } \\
\text { road/ community } \\
\text { access road }\end{array}$ & - & $12-25$ \\
\hline
\end{tabular}

(Source: [9])

Area 2: Road cross section design

The Plan and Current situation: all cross sections of the proposed roads are designed and built according to the requirement.

Area 3: Static traffic system

The Plan: There will be six(6) public parking areas and two(2) bus stations proposed for Haidian island. The location of public parking areas are not specified in the plan while the bus stations had been determined to be located at south of Baishamen wastewater treatment plant and east of Haidian Road 2.

Current situation: Bus station at south of Baishamen wastewater treatment plant had been built and in-use but the other one at East of Haidian Road 2 is not constructed but replaced to a new location underneath the Century Bridge as showed in Figure 4 and 5.

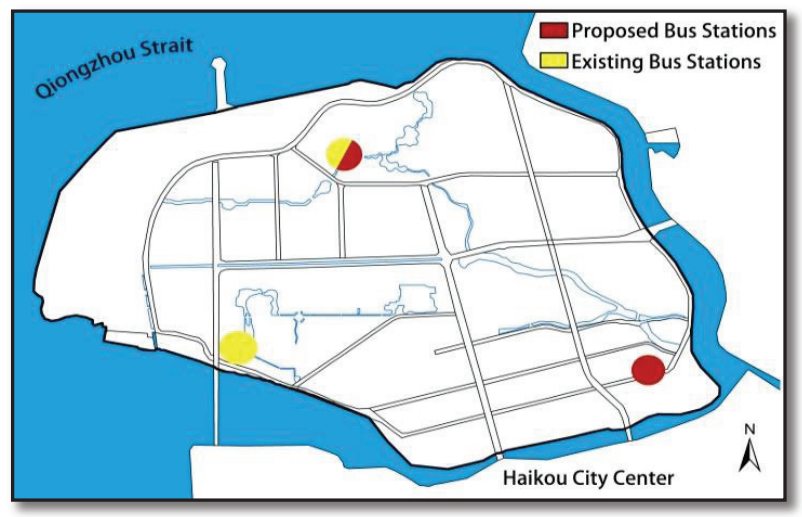

Figure 4. Bus station location (Source: [9], author added-on)

\section{Area 4: Slow transit system}

The Plan: walking, cycling and skating are three major slow transportation systems that highlighted in the Plan. In line with the 'green and low carbon' development concept, the government intended to build the basic infrastructures that accomplished with the above mentioned slow systems for healthy lifestyle of the islanders. Table 2 showed the proposed development areas for these slow transportation systems.

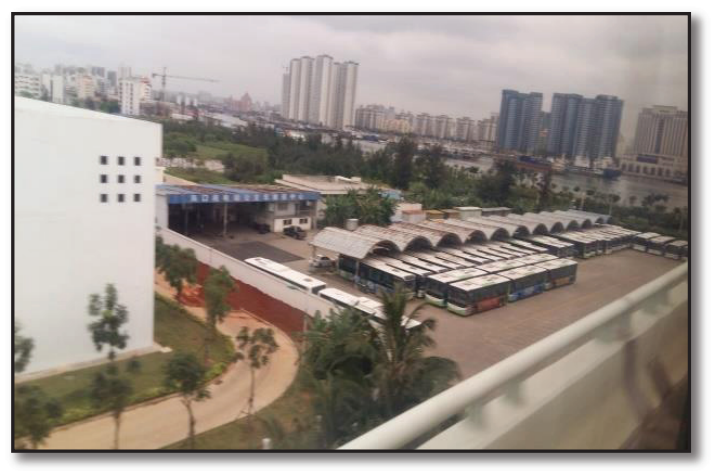

Figure 5. Bus station underneath Century Bridge. (Source: author photograph)

Table 2. Proposed walking, cycling and skating system for Haidian island

\begin{tabular}{|l|l|l|}
\hline & $\begin{array}{l}\text { Transit } \\
\text { system }\end{array}$ & Area covered \\
\hline 1 & $\begin{array}{l}\text { Walking } \\
\text { system }\end{array}$ & $\begin{array}{l}\text { Bihai avenue, Haida Road, Yixin Road, } \\
\text { Baisha River, Moon River }\end{array}$ \\
\hline 2 & $\begin{array}{l}\text { Cycling } \\
\text { system }\end{array}$ & $\begin{array}{l}\text { Classic Route: Baishamen Park, Hainan } \\
\text { University, Heping Avenue and Haidian } \\
\text { Road 1 etc; } \\
\text { Ring Road: Bihai Avenue, Haidian } \\
\text { Road 1 etc }\end{array}$ \\
\hline 3 & $\begin{array}{l}\text { Skating } \\
\text { system }\end{array}$ & Northern Seaside of Baishamen Park \\
\hline
\end{tabular}

(Source: [9])

Current situation: Till now, cycling and pedestrian paths are constructed gradually according to the plan. However, some of the paths had been cut off, especially those at the southern part of Hainan University and along Haidian stream caused by rapid housing development that affects the width of road reserve to be reduced.

Area 5: Water and cruise transport

The Plan: A number of cruise jetties are proposed to be located along the coastline surrounding Haidian island. No fix location is specified on plan but according to 'Haikou Yacht and Cruise development plan (2011 2020)', two marinas were proposed to be built at the western part of Haidian island, one of it is a private marina while the other one is an integrated terminal (Figure 6) [10] .

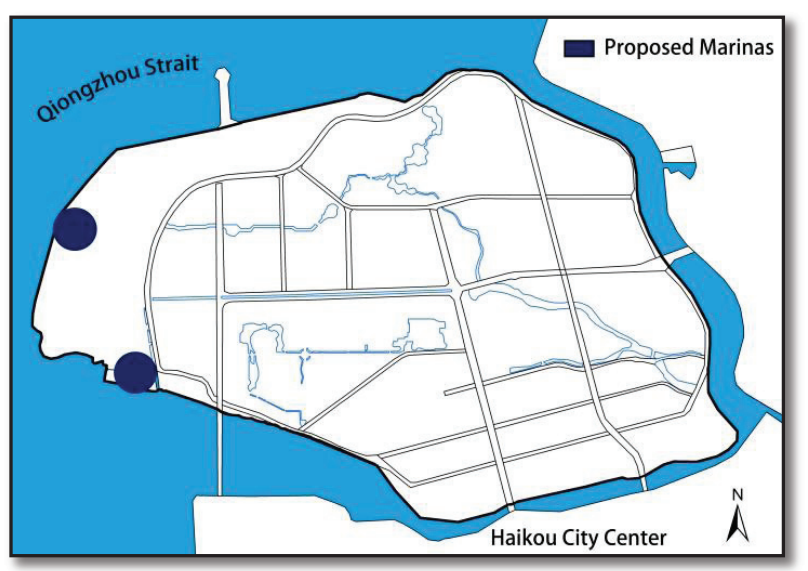

Figure 6: Proposed marinas in Haidian island (Source : [10] ) 
Current situation: Up-to-date, there is one marina under construction at the south-western part of Haidian island, which is on the location for the proposed 'Danna marina'. Also, along the Haidian stream at southern part of Haidian island, there is a harbor for local fishing boats/ships (Figure 7).
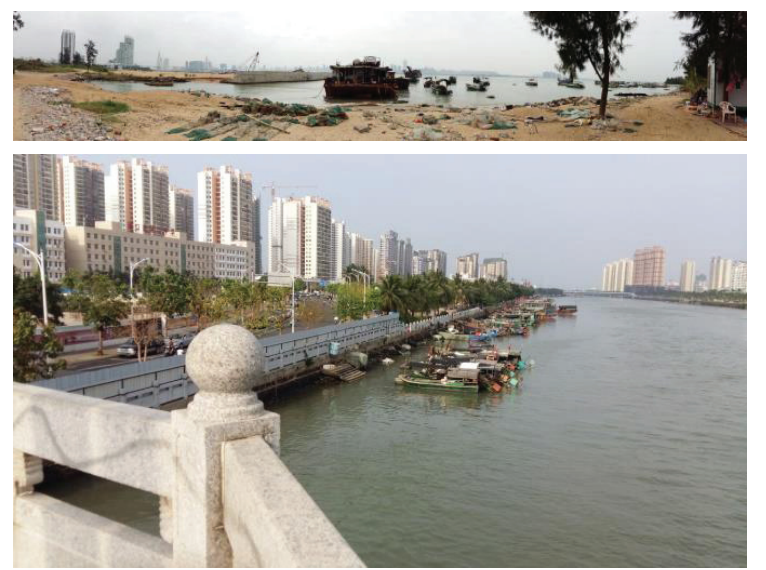

Figure 7. (Above) Danna marina under construction and (Below) existing habor for fishing boats

(Source: author photograph)

\section{Area 6: Traffic control planning}

The Plan: The use of truncation area at junction for development is prohibited. Opening for ingress and egress are proposed to be every $200 \mathrm{~m}$ for trunk road and $100 \mathrm{~m}$ for arterial road.

Current situation: No fouls are found. Area 7: Vertical traffic planning

The Plan: In order to reserve sufficient space for future drainage system, flood protection, traffic safety and municipal engineering work etc, the plan determined the control standard for road elevation and slope should be larger than $0.5 \%$ or at least $0.3 \%$ if situation is difficult. For new developed area, elevation and slope could be higher 0.5 meter than the normal level.

Current situation: This rule had been followed accordingly.

\section{Area 8: Road intersection}

The Plan: There are four intersections found in Haidian island with the design of footbridge on top for pedestrian and $\mathrm{T}$-junction on ground for vehicles. In addition, all intersections of trunk-trunk road, trunk-arterial road would use traffic light as control elements while for local distribution road and community access road, right turning road are designed to deliberate traffic.

Current situation: Table 3 showed the existing intersections and it's traffic flow during site investigation. The observation result showed that Haidian Road 2 and 3 has heavy human and non-motorized vehicles flow while Haidian Road 5 has more motorized vehicles flow during peak hours.

\section{Area 9: Footbridge proposal}

The Plan: The plan suggested for two overhead foot bridges to be built at; i) intersection of Haidian Road 2 - Renmin Avenue and ii) intersection of Haidian Road 5 Renmin Avenue.
Current situation: Up-to-date, the Haidian Road 2 Renmin Avenue overhead bridge had been completely constructed (Figure 8) but the other overhead footbridge at intersection of Haidian Road 5-Renmin Avenue had not been constructed.

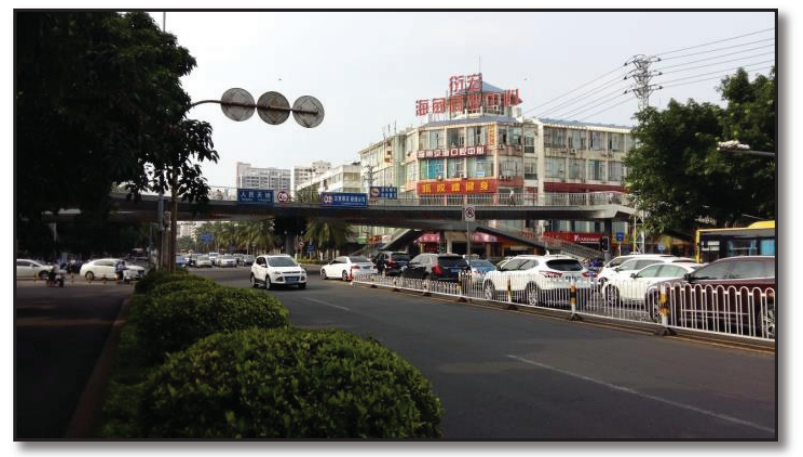

Figure 8. overhead footbridge at intersection of Haidian Road 2 -Renmin Avenue (Source: Author photograph)

\subsection{The problems}

The study found several problems from the implementation of the 'Haidian Island Area Development Control Plan' as discussed above which could be summed up as below.

Table 3. Human, Motorized and Non-motorized vehicles flow at Intersections during Peak hour

\begin{tabular}{|l|c|c|c|}
\hline $\begin{array}{l}\text { Evening Peak } \\
\text { hour }\end{array}$ & $\begin{array}{l}\text { Human } \\
\text { Flow } \\
\text { (p/h) }\end{array}$ & $\begin{array}{l}\text { Motor } \\
\text { vehicle } \\
\text { Flow } \\
\text { (pcu/h) }\end{array}$ & $\begin{array}{l}\text { Non-motorized } \\
\text { vehicle Flow } \\
\text { (Bicycle and } \\
\text { electric bike) } \\
\text { (pcu/h) }\end{array}$ \\
\hline $\begin{array}{l}\text { Intersection of } \\
\text { Haidian Wuxi Road } \\
\text { and Century } \\
\text { Avenue }\end{array}$ & 300 & 3720 & 1680 \\
\hline $\begin{array}{l}\text { Intersection of } \\
\text { Haidian Wuxi Road } \\
\text { and Renmin } \\
\text { Avenue }\end{array}$ & 300 & 3540 & 5880 \\
\hline $\begin{array}{l}\text { Intersection of } \\
\text { Haidian Road 3 } \\
\text { west and Renmin } \\
\text { Avenue }\end{array}$ & 2880 & 1560 & 4140 \\
\hline $\begin{array}{l}\text { Intersection of } \\
\text { Haidian Road 2 } \\
\text { West and Renmin } \\
\text { Avenue }\end{array}$ & 1560 & 2820 & 5940 \\
\hline $\begin{array}{l}\text { Source: Author obsenva } \\
\text { (p) }\end{array}$ & & & \\
\hline
\end{tabular}

(Source: Author observation result)

\subsubsection{Long one-way routes}

Two major trunk roads, Haidian Wuxi road and Renmin Avenue, are both long and one-way traffic road for motorized vehicles with six carriageways (three lanes each for one side). Vehicles that wish to cross over to the opposite side of the road need to travel to the intersection at both end of these two roads to make the turning (Figure 9 ), that caused congestion at the intersection with through and u-turn traffic[11]. In addition, there is one u-turn 
opening at Renmin Avenue are designed at traffic light junction also caused some serious issues, i. Collison of traffic between on-coming traffic and u-turn traffic; ii. U-turn radius not enough for even normal car to make a turn within one turning (Figure 10).

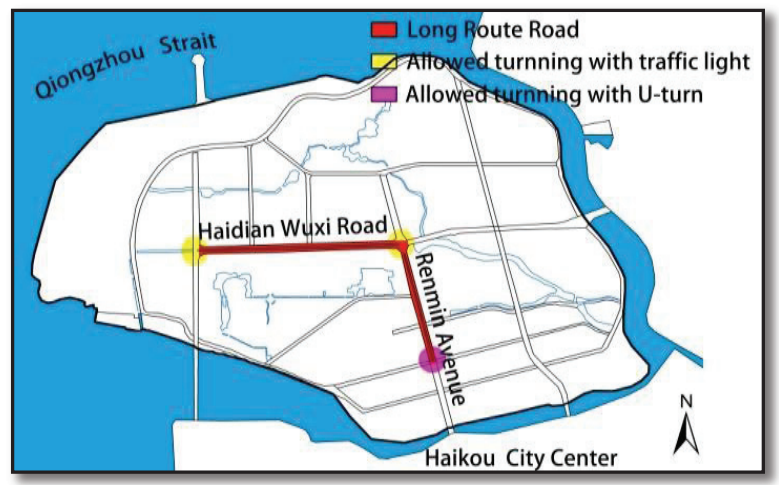

Figure 9. Long route without turning at Haidian Wuxi Road and Renmin Avenue (Source: author survey)

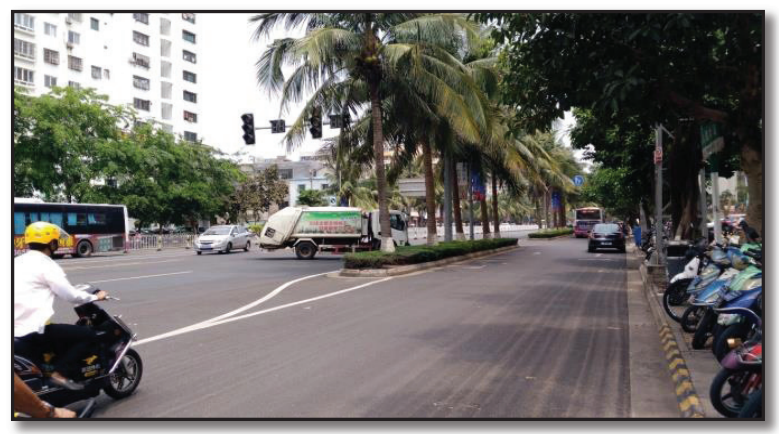

Figure 10. Dangerous turning at Renmin Avenue (Source, author photograph)

\subsubsection{Uncontrolled right turning of vehicles}

As stated above, right turn traffic flow is not been controlled by traffic light at any roads, is a practice in China[12]. This practice caused motorized vehicles to collide with other road users especially pedestrians[13]. Pedestrians cannot cross over the street even with zebra crossing (Figure 11).

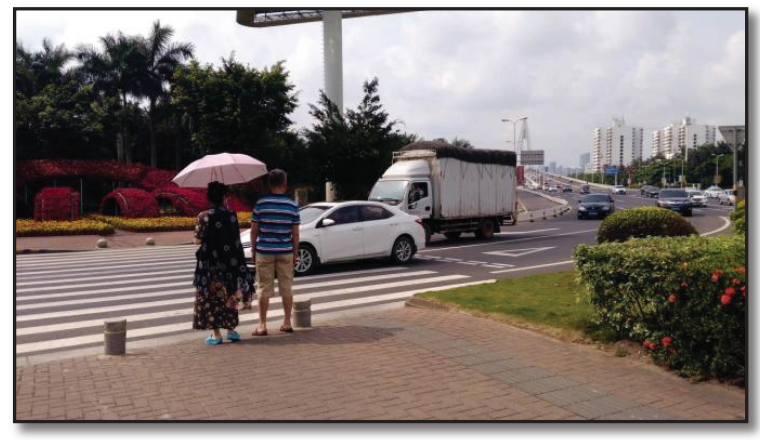

Figure 11. pedestrians at zebra crossing cannot cross the street caused by non-stop right turn vehicles. (Source: author photograph)

\subsubsection{Congestion at intersections}

Even though the site investigation found that there were no heavy traffic flow of motorized vehicles even during peak hour, but there is still, congestion at intersection, particularly with non-motorized transport (especially the electric bike) and pedestrians (Figure 12)[14]. This congestion become worst with uncontrolled right turning vehicles and usually caused minor accidents here and there at the intersections.

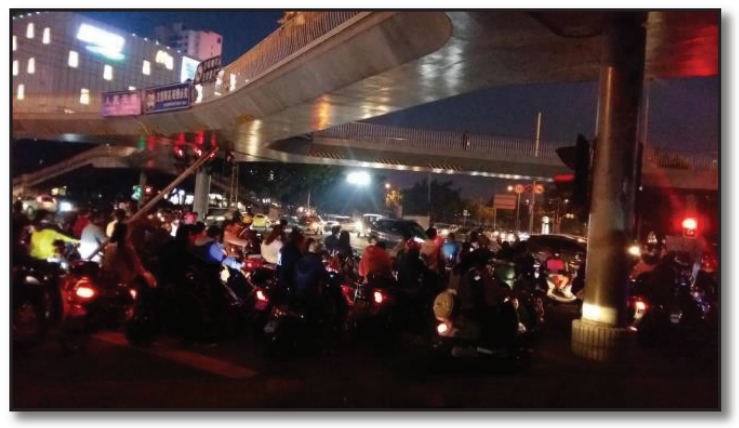

Figure 12. Congestion at intersection of Haidian Road 2-Renmin Avenue during evening peak hour.

(Source: author photograph)

\subsubsection{Incomplete pedestrian and cycling paths}

From the site investigation, there are some significant issues with pedestrian and cycling paths within the island, which are:

- Break off of pedestrian and cycling paths due to expansion of road or reduction of road widths.

- Cut off of pedestrian and cycling paths due to motorized vehicles parked on the pedestrian paths and road side car parking that occupied the cycling paths.

- Collision between pedestrian and bicycle on pedestrian paths.

\subsubsection{Lack of touristic direction signboards}

There are insufficient of signboards within the island which provide proper and exact direction to road users, especially the tourists. Baishamen park and Hainan University are two major attractions in Haikou city which attracted local and international tourists to visit especially by foot or bus. No direct public bus services from city centre to these attractions caused the tourists to ask around for directions when come nearby to these locations. Therefore, touristic signboards are important to guide them not to get lose and get organized[15].

\section{Improvement plan}

To enhance the 'Haidian Island Area Development Control Plan', the paper put forward some suggestions as below.

\subsection{Awareness in driving and pedestrian safety for the people}


Drivers (of motorized and non-motorized transport) and pedestrians are the major users of the road. Both parties should work together to ensure safety of each others. Awareness campaign should be carried out time to time in public or the university, to remain people of maintains good habits on road[16], [17]. Road safety is not just slogan to look at but to practice on. Chinese road users need to improve their on-road behavior to guarantee smooth traffic, particularly the pedestrians. Obviously, pedestrians on Haidian island would cross the road without following traffic instructions which messes up the road condition and eventually caused accidents to happen. Governmental authorities, private enterprises and public should work hand-in-hand to boost the awareness of general public.

\subsection{Prohibition of young drivers}

Nowadays, the riding of electric bike in china does not have any age restriction. Neither to obtain a driving license. As the usage of electric bikes are very common in China, some restrictions should be implied to ensure safeness. The rider for electric bike should followed the provision for 'application and usage of motor vehicle driver's license' which stated the minimum age to applied for license is 18 years old and should passed the all relevant examinations [18]. As we can see today, young electric bike riders, especially primary and middle school students which below the minimum age should not be allowed on road because they does not have enough knowledge, self-control and consciousness in making real time reaction to immediate traffic situation.

\subsection{Completion of round island cycling and pedestrian paths}

'Green city, low corban' concept encourages more walking and cycling, less driving. In conjunction to this, round island cycling and pedestrian paths need to be completed, for at less two purposes; i. islander daily usage and ii. Tourist, such as suggested by Cheng for Xiamen[19]. Figure 13 showed the proposed cycling and pedestrian paths for Haidian island, basically round island. Walk paths should be extended in all directions within the island while the cycling paths can be specified into two categories, daily route and tourist route.

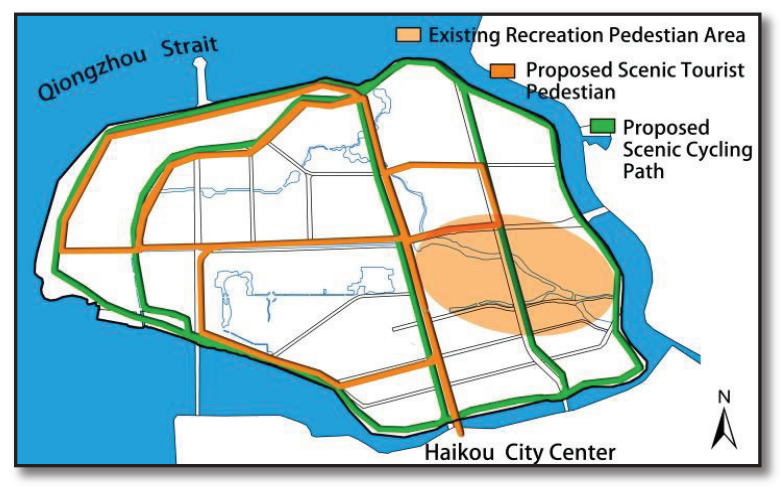

Figure 13. Proposed round island cycling and pedestrian paths (Source: author illustration)

\subsection{Introduction to touristic routes and signages}

There are several touristic attractions in Haidian island such as Baishamen park, Hainan University while Haikou Qilou Arcade street and Haikou old city centre is located at the adjacent location, which formed the 'Golden Triangle for Haikou Day-trip' destination. Therefore, guide-orientated signages should be located along the way, from the old city centre to Baishamen park, through Hainan University. In order to exalt tourism activities on Haidian island, touristic routes should be created to help tourist enjoys scenery view of Haidian island.

\subsection{Promote the use of non-motorize and public transit}

Again, green and low carbon are the concept for tomorrow city, Haikou too has the same vision. Some improvement actions are recommended to enhance this vision, including:

- Increase the regularity of bus service duration and familiarize the bus drivers with knowledge of all bus routes and ability to give advices to passenger with smiling face at all time.

- Improve basic infrastructures for bus stops and facilities along the way to bus stops, rain shed, sitting bench, lighting, trash bin, route schedule, directional and guide tile etc that provide cozy environment and encourages people to use public transport (Figure 14).

- Bike sharing project is now undergoing in China which is a big step forward in promoting low carbon concept, however, awareness for people to use and park in right manner is important to maintain the bike sharing to be sustainable (Figure 15).

- Electric bike users should be advised to follow motorcycle rules and regulations on driving and parking as both of these vehicles share many common similarities.

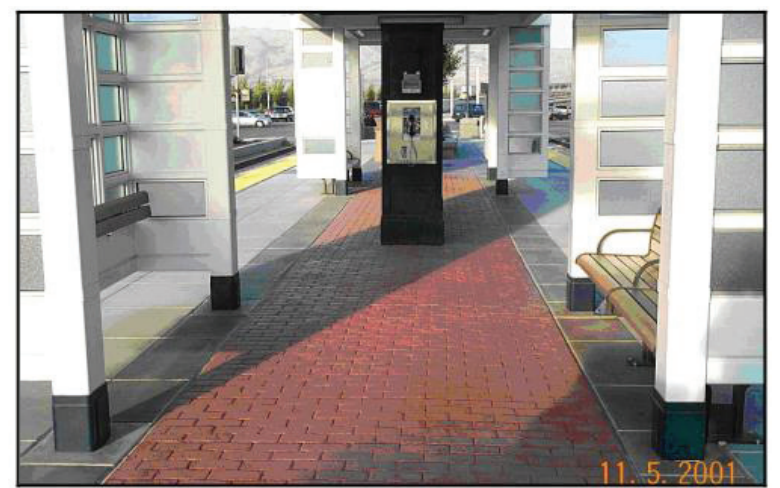

Figure 14. Public bus shelter integrated with pedestrian path (Source: [20]) 


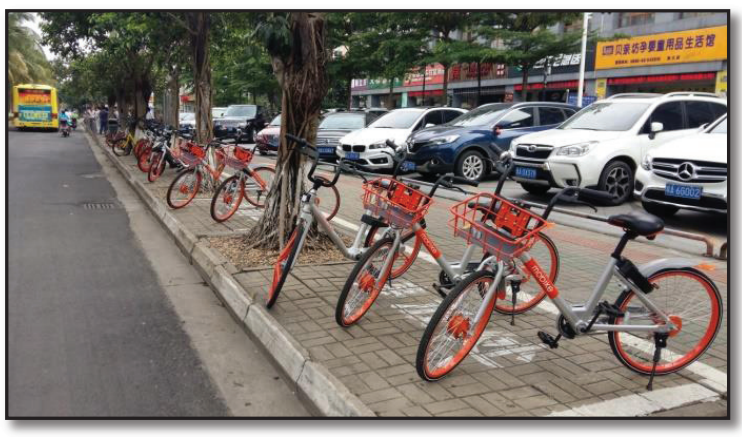

Figure 15. Bike sharing at Haidian island

(Source: author photograph)

\section{Conclusion}

Mass transit and Non-motorize transport are the trend of future that responses to sustainable urban transportation planning[21-23]. People are advised to adapt with the shift from small and private vehicles that pollute the environment to an energy saving and healthy lifestyle of cycling and walking. The city is changing, bike sharing project shows a good start for people to move around, work and leisure. More effects on 'green travel, low carbon' are going to implement by the authorities but more important of all, is the awareness, adaptation and change of attitudes of the people to follow the path of the government, in the initiative of sustainable urban transportation planning for better future. The Haidian island improvement plan as suggested by the researchers take into consideration landuse, people and authourities, integrating non-motorized vehicles with cycling and pedestrian, is able to bring better living environment for the islander from now and to the future.

\section{References}

1. H. Pan, The characteristics of Traffic Problems in Development Middle cities. Urban Planning Review, 1998, (2):24 -29, (1998).

2. B. Wang, Application of New Technology in Urban Transportation Planning. Transport World, (14):62-63, (2015).

3. Y. Yan, Brief discussion on road reconstruction and construction technology. Science and Wealth, (4):304, (2012).

4. H. Hua, New urban district traffic planning strategy under low carbon traffic. Knowledge of Architecture, (B04):67\&69, (2013).

5. Government of China, Several opinions of the State Council on promoting the construction and development of Hainan International tourism island. Retrieved on 2017-04-26, http://www.gov.cn/zwgk/2010-01/04/content_150253 1.htm, (2010).

6. Hainan History Network, Hainan Profile. Retrieved on 2017-04-27, http://www.hnszw.org.cn/data/news/2014/12/75985/, (2008).
7. S. Liu, Look at the world, Haidian island (In Mandarin). Hainan Daily,2007-08-16 (15), (2007).

8. Haikou Municipal Government (2005) Haikou City Master planning, 2005 -2020. Haikou: Haikou Municipal Government. June, (2005).

9. Haikou Urban Planning Bureau.Development control planning for Haidian Island Area, Haikou. Retrieved on 2017-04-22, http://www.hkup.gov.cn/ghcgshow.asp?smallclass Na $\mathrm{me}=\% \mathrm{BF} \% \mathrm{D} 8 \% \mathrm{~B} 9 \% \mathrm{E} 6$ \&id=7010\&Page $=2$, (2012).

10. Haikou Tourism Development Committee, Haikou Yacht and Cruise Industry Development Plan (2011 2020), Haikou: Haikou Tourism Development Committee, (December, 2011).

11. R. Liu, Queuing Molde for U0turn mouth of Bi-directional streets. Journal of Chongqing Jiaotong University (Natural Science), 28(5):921 -925, (2009).

12. Y. Bao, Z. Zhou, \& Y. Xu, A Conflict Model involving right-turning vehicles and cross-walking pedestrians at signalized intersections. Journal of Transport Information and Safety, (3):41-49, (2016).

13. Y. Ni \& K. Li, Dealing with conflict between pedestrian and right turning vehicle in signalized intersection. Computer and Communication, (1):22-26, (2007).

14. Y. Liu, Studies of Improvement for traffic safety at Urban Signalized Intersections based on cyclist have priorities. Xi'an: Chang'an University, (2012).

15. X. Wang, Knowledge of Signage. Forest \& Humankind, (12): 88-95.

16. S. Chai, Popularize traffic safety knowledge among universities students. Charming China, (15):34, (2011).

17. J. Li, Traffic safety into university campus. Road traffic Management, (1):74, (2016).

18. The ministry of public security of the People's Republic of China, The decision to the amendment of application and usage of motor vehicles license. Retrieved on 2017-04-25, http://www.mps.gov.cn/n2254314/n2254409/n49043 53/c5171192/content.html, (2016).

19. J. Cheng, Landscape creation on seaside road in cities: with landscape design on Huangdao Road in Amoy as an example. Planner, (5):71-74, (2004).

20. Santa Clara Valley Transport Authority. Bus stop and passengers facilities standards. Retrieved on 2017-04-25.

http://vtaorgcontent.s3-us-west-1.amazonaws.com/Sit e_Content/VTA $\% 20$ Bus $\% 20$ Stop $\% 20$ Passenger $\% 20$ Fac\%20Stds\%202010.pdf, (2010).

21. R. Sia, B. Wu, \& J. Li, Mass transit as urban tourist transport. Applied Mechanics and Materials, 97-98:1131-1134, (2011).

22. H. Guo, The city needs friendly slow traffic. Neijiang Technology, (2):121-122, (2016).

23. L. Qian, The fundamental to solve urban transport problems is to develop public transport in scale. Beijing City Planning \& Construction Review, (6):25-27, (1998) 